\title{
QR Code and the Wine Sector: What Contents? An Exploratory Research Study on the Wine Industry
}

\author{
Diletta Acuti, Lorenzo Magherini, Valentina Mazzoli, \\ Romeo Bandinelli, Raffaele Donvito, Rinaldo Rinaldi \\ and Gaetano Aiello
}

\begin{abstract}
This paper presents an explorative analysis of the contents shared through QR codes as a tool of proximity marketing. The aim of the research is to identify the most common links shared through the QR code technology, in order to investigate the use of this tool from a marketing point of view. Moreover, the research explores the main aspects of the communications related to the contents shared through QR codes. Specifically, the authors focus on hedonic aspects and functional ones. Finally, the research aims at identifying preliminary best practices in the use of QR code technology. Due to the widespread use of this tool in the sector, the research focuses on the wine industry, as one of the most involved with QR code practices. The study adopts a qualitative approach based on a content analysis of 91 wine labels. Considering the importance of this integrated communication, the purpose of this explorative analysis is to deduce implications that enable managers to master the use of this tool, exploiting all its potential.
\end{abstract}

Keywords Wine - Marketing - QR code - Social media • N-vivo • Winery • Traceability • Content marketing • Tourism • Sustainability

\section{Introduction}

We often characterize the agro-food industry as one with little value-added and little innovative content. In such a globalized world, this sector contains considerable opportunities for technological and rent upgrading. As confirmed by recent research (Farinelli 2012; Kaplinsky and Fitter 2004; Kaplinsky and Readman 2005), there is

D. Acuti · V. Mazzoli · R. Donvito

Economics and Management Department, University of Pisa, Pisa, Italy

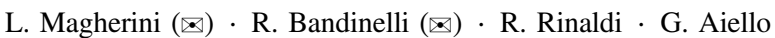

Industrial Engineering Department, University of Florence, Florence, Italy

e-mail: lorenzo.magherini@unifi.it

R. Bandinelli

e-mail: romeo.bandinelli@unifi.it

C) Springer International Publishing AG 2017

R. Rinaldi and R. Bandinelli (eds.), Business Models and ICT Technologies for the Fashion Supply Chain, Lecture Notes in Electrical Engineering 413, DOI 10.1007/978-3-319-48511-9_24 
an ongoing process of de-commodification of primary goods, which are increasingly being transformed from everyday staples into high quality products, diversified both in terms of aesthetics and for the changing needs of consumers (e.g., the tendency of some adults to develop vegetarian or vegan dietary habits). Others become processed products by means of the accumulation of greater knowledge and technological progress, which increase the value of content shown as well as the export price per unit. Wine is one of the most interesting cases from a catch-up point of view, because the latecomers in the international market have changed how wine is produced, sold, and consumed and, in doing so, they have challenged the positions held by the incumbents (Giuliani 2011).

Wine is produced, sold, and consumed globally. The quality of the wine, as an agricultural food product, is closely tied to the nature of the original crop (i.e., the grapes). For this reason, wine production is highly dependent, on and influenced by, geographical characteristics.

At the same time, its sales are being developed via marketing strategies that tend to emphasize the characteristics of the production area, the techniques used, the handmade aspects, etc.

In the wine industry this is referred to as terroir.

Terroir is more complex than merely location. It involves climate, soil, tradition, terrain, and even culture by some definitions.

The concept of terroir captures such diversity coupled with history and tradition (Charters 2006), and confers on a certain type of wine a unique competitive advantage over other producers (Wilson 1998; Vaudour 2002; Barham 2003). Wine producing countries, under the regulations of the EU commission, have introduced several schemes and legislation protecting the place of origin of wines and regulating its production in many aspects, ranging from maximum yields per hectare, oenological practices, grape varieties, and the labelling of wine among others. As an example, in Italy the regulation can affect, besides the already mentioned, even the oenological (cuts, practices, etc.), product specification (production area, type of grape, wine-growing practices, and winemaking methods), the permitted indications (DOP, IGP), national endorsements (i.e., DOC for Italy, AOC for France AOC), and authorization to name a wine with the region of origin (i.e., Asti, Porto, Champagne).

The competitive dynamics of the wine market are complex (Orth and Lockshin 2007): the scenario has expanded into a global competition for consumer's taste preferences and on hedonic and emotional aspects, as well as on aspects related to health and sustainability. These innovative dynamics are changing wineries' strategies. Marketing innovation will be important in order to build competitive advantage and achieve growth (Chen 2006). Wineries are recognizing the need to acquire more environmentally efficient technologies on the one hand, and ensure proper management of the product traceability in order to use it as a marketing strategy for the consumers, on the other. RFID technology is one of the developing frontiers in this sector as it will make the wine supply chain completely transparent and advise consumers on the origin and processing of a bottle. The issue of sustainability, both in primary production processes (grape growing) and in its 
transformation (wine-making), is taking a central role in the operational and strategic choices of wineries, because of the increasing concerns about the environment, ecological consequences, and the efficient use of natural renewable resources as reflected in public opinion and consumers' perceptions (Pilone et al. 2015). This can be used as an important marketing strategy.

There are many studies that highlight the influence that the innovative approach has on the winery's ability to improve the satisfaction level in meeting the consumer's expectations (Santini et al. 2007).

\section{Literature Review}

Consumer habits are changing as result of new technologies used in day-to-day life (Grewal et al. 2012) and, as a consequence, consumer goods companies are developing new ways of relating to their customers (Peira et al. 2012). Because of the progress and the spread of new technologies, communication strategies have undergone an evident revolution. Mobile diffusion has not only changed the way in which organizations and their brands interact with customers, it has also changed the way business gets done: they are able to reach consumers with digital tools and network with them (Begalli et al. 2012). This is one of the reasons why recent years have witnessed growing interest of marketers in mobile phone as a channel of marketing communication, and it will continue to gain marketers attention even further (Wohlfahrt 2002). The specific characteristics of mobile phones like geo-targeting, ubiquity, immediacy, customization, measurability, and interactivity encourage using mobile phone in hardcore marketing (Bauer et al. 2005; Haghirian et al. 2005). Apart from the above modes of mobile marketing, one very innovative mode that has been catching marketers' attention recently in current digital space, i.e. QR codes (Bamoriya 2014). QR code is an abbreviation for Quick Response Code. Basically it's a 2D code, which, once scanned by a Smartphone-with a scanning application software-connects users to some specific online content on a website, linking to an email address, delivering e-coupons, texting, leading to registration, and so on (Handley 2012; Bisel 2011). Due to the convenience, user-friendliness, multiple fields of application, and customer-driven information provided by mobile tagging, it has become the key technology for mobile surfing (Shiang-Yen et al. 2013). Indeed, product knowledge is a key concept in consumer behavior and consumer decision making, and QR codes have the ability to deliver and share information at the point of need (Raju et al. 1993). QR Codes are a good fit for almost any sector, but for wine they offer a particular benefit (Brabazon et al. 2014). Indeed, the wine sector is challenging the Wine 2.0 era, using the Internet to engage with wine consumers on their terms, in a time and manner of their choosing (Olsen and Hermsmeyer 2008). Tools usually include social-networking sites, blogs, message boards, and other methods that leverage user-generated content. Wine is an experiential good that cannot be fully evaluated until it is consumed, thus in the absence of tastings or prior experience with the wine, the purchase 
decision is challenging for many wine consumers (Cooper-Martin 1991). Now, thanks to technology, wine purchasing has become part of the information era (Halstead 2013). The importance of using QR codes in the wine sector is due to the peculiar characteristics of this product: many consumers do not simply buy a bottle of wine on the shelf for its particular use; they buy its heritage, quality, territory, production processes, and specific organoleptic features.

Wine is recognized as a lifestyle beverage, and the wine consumer's relationship therewith is based on an acquired, not an innate need, as in the cases of food and water. Wine consumption itself can be regarded as a hedonic experience for some people-an emotional and pleasurable activity aimed at personal enjoyment (whether of a basic wine drinker or a connoisseur) within the context of a myriad of potential social experiences (Bruwer and Alant 2009).

For these reasons, communicating the experience of hedonic goods involves a large portion of the retail marketing strategy, such as managing asymmetric information (Akerlof 1970; Nelson 1970) and resolving this asymmetry through the use of price and advertising (Milgrom and Roberts 1986; Nelson 1974), warranties (Grossman 1981), and expert opinion (Cuellar and Claps 2013; Eliashberg and Shugan 1997; Reinstein and Snyder 2005).

The consumer interest in wine content varies depending on the scanning time: QR codes are not only useful at the point of sale (Brabazon et al. 2014), but also during the consumption. Hence, shared contents should vary depending on the scanning time, considering the trade-off between the hedonic aspects and functional aspects of the product (Ferrarini et al. 2010). Moreover, contents may vary depending on brand awareness of the wine. In the literature, studies have investigated the wine sector from various points of view (Lockshin and Corsi 2012) retailing, purchasing, tourism (Bruwer and Alant 2009), lifestyle, packaging and labelling, region (Easingwood et al. 2011), sustainability (Forbes et al. 2009), technology (Brabazon et al. 2014), social media (Reyneke et al. 2011) —but there is a gap regarding the contents taxonomy that wine companies communicate to consumers through new digital tools. This exploratory research investigates this issue within the context of the Italian market.

\section{Methodology}

This exploratory analysis of the uses of QR codes in the wine industry adopts a qualitative approach through a content-analysis methodology (Berelson 1952). Authors scanned 91 QR codes of Italian wine brands purchased from three large stores of grocery retailers located in Tuscany and classified the contents in terms of website homepage or specific website page, the technical file of the wine, or other pages (Yoo and Kim 2014; Shobeiri et al. 2014; Geissler et al. 2006). Hence, authors focused only on website homepages and website technical files of the products with the intent of examining specific hedonic (Alba and Williams 2013; Hirschman and Holbrook 1982) and technical aspects of each category (Sheth et al. 1991). 
In particular, the scientific authors codified hedonic aspects, i.e., contents aiming at stimulating an emotional response from consumers, in terms of fun, amusement, fantasy, arousal, sensory stimulation, and enjoyment (Hirschman and Holbrook 1982).

Technical or functional aspects are considered specific features or characteristics of the product, the production, or the winery.

The mind map of the content analysis is specified in Fig. 1. The nodes of classification have been identified top-down (hedonic features and technical feature), and bottom-up (website homepage, website technical file of the product, heritage, quality, territory, certification, sustainability, functional aspects, and organoleptic aspects).

The content analysis has been carried out with N-ivo software (Bazeley and Jackson 2013).

Authors, once codified contents retrieved from QR code links in terms of hedonic and technical aspects and created the respectively nodes, run a word frequency query within the nodes in order to identify the main lemmas used for the website communication.

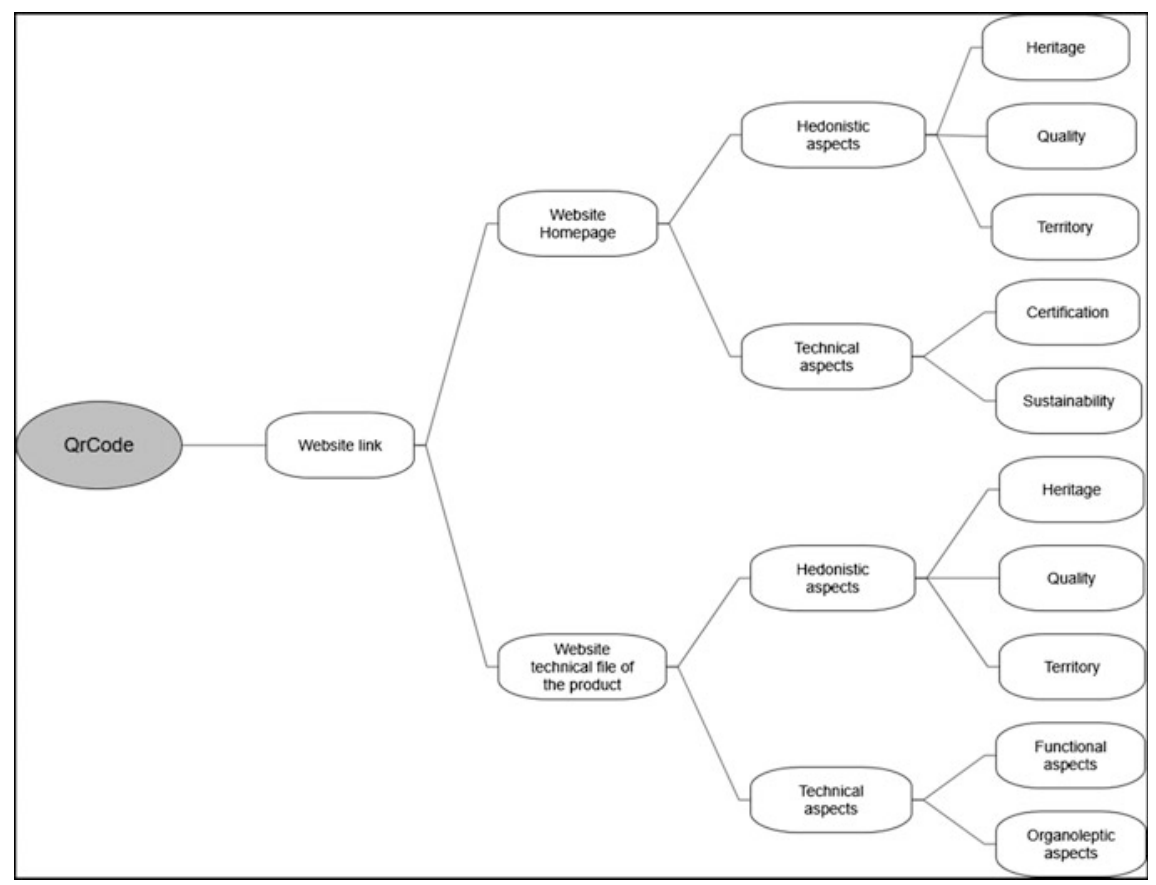

Fig. 1 Concept map of content analysis 
The codifying process has been carried out separately by two research who then compared the results with NVivo intercoded reliability function in order to assess the consistency of the codification. The average of the intercoded reliability index within various nodes of codification is $97.0 \%$.

Finally, the authors focused on contents relying on the degree of brand awareness based on official rankings, with the aim to identify a benchmark of best practices within the sample considered. The authors assume there is a relationship between typology of content shared and typology of brand analyzed, in particular, since it was assumed that the consumers of renowned brands are more aware of QR code technology.

Considering the phases previously discussed, the research questions that this study addresses are:

RQ1 What kind of links are shared through QR codes in the wine industry?

RQ2 What aspects of the communication are stressed in the contents shared through QR codes in the wine industry?

RQ3 What are the best practices in terms of QR code use in the wine industry?

\section{Main Results}

Considering RQ1, the typology of links shared are brand website pages, Google Search, or other pages, such as wine associations' websites or the YouTube channel. In some cases, the category "other pages" refers to not identified pages, thus showing a wrong use QR code. Focusing only on brand website pages, the results show that most part of contents matches to the website homepage (42\%) and the technical file of the wine 37 (Table 1).

Considering RQ2, authors analyzed the aspects of the communication stressed by wine brands in terms of hedonic and technical aspects.

Technical files of the wine belong to two different types: the written one (a written page describes wine features) and the spoken one (a video describes wine features). Video generally are not limited to the functional aspects of the wine, but they try to stress also the hedonic and emotional aspects of wine consumption.

Table 1 Sample composition

\begin{tabular}{l|l|c}
\hline QR code content & Number of wine labels & \multicolumn{1}{l}{} \\
\hline Website homepage & 38 & 41.8 \\
\hline Website technical file of the wine & 34 & 37.4 \\
\hline Google search & 8 & 8.8 \\
\hline Other pages & 9 & 12.1 \\
\hline Total & 91 & 100.0 \\
\hline
\end{tabular}




acidity ageing area bottles bottling bouquet certified collaboration COlOUr combination conservation
controlled days denomination excellence fermentation food fragrance
freshness glass gradation harvest maceration months must production proof
quality $\mathrm{PCO}$ sangiovese steel strength system temperature White
Wine winery wood worth

Fig. 2 Technical file: tagcloud within technical node

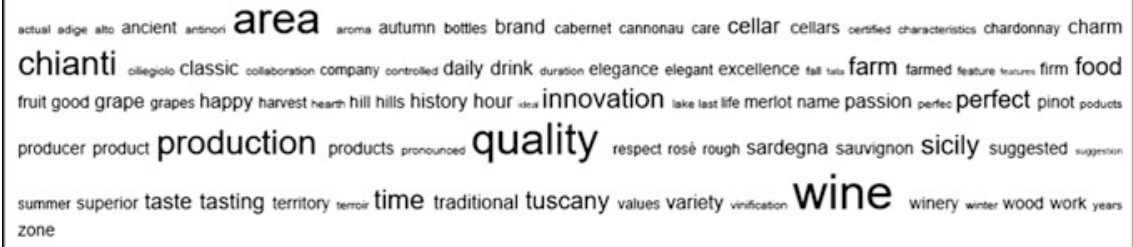

Fig. 3 Technical file: tagcloud within the hedonic node

In addition, written technical files seek to mix the two aspects, but in the largest part of cases, wineries limit the description only to specific functional and organoleptic aspects, such as area of production, terrain, grapes, vinification, color, aroma, and taste. Besides, in some cases, wineries seek to evoke also hedonic aspects, such as the heritage and tradition of the brand. However, functional and organoleptic aspects are more consistent.

In order to derive the main lemmas used in the technical file, Figs. 2 and 3 summarize this information.

Technical associations in technical files of the wine are strongly related to the processes of the production (i.e., wine harvest, maceration, fermentation, ageing) and to the main features of the wine (i.e., color, gradation, acidity).

The most important associations retrieved in the hedonic node of the technical file stress the role of the quality through the innovation of the production used in the territorial area of the winery's cellar.

The same criteria drove the content analysis on website homepages. In this case, hedonic aspects are predominant, focusing on images and text that evoke brand values such as the quality of the production resulting from the strong links to the territory and the brand heritage. The technical aspects identified in this case are certifications (Igt, DOC, DOCG, or Organic Production) and sustainability procedures. 


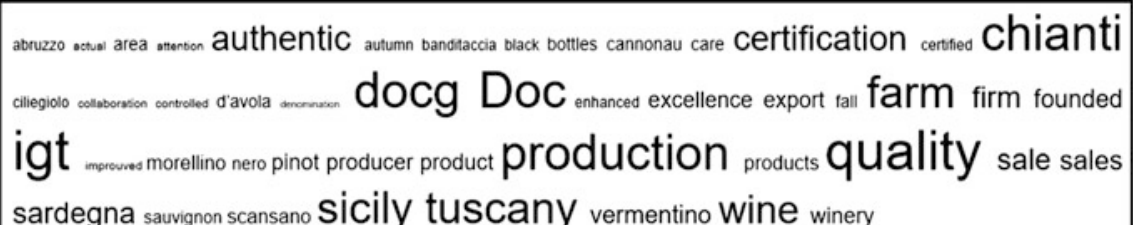

Fig. 4 Homepage: tagcloud within technical node

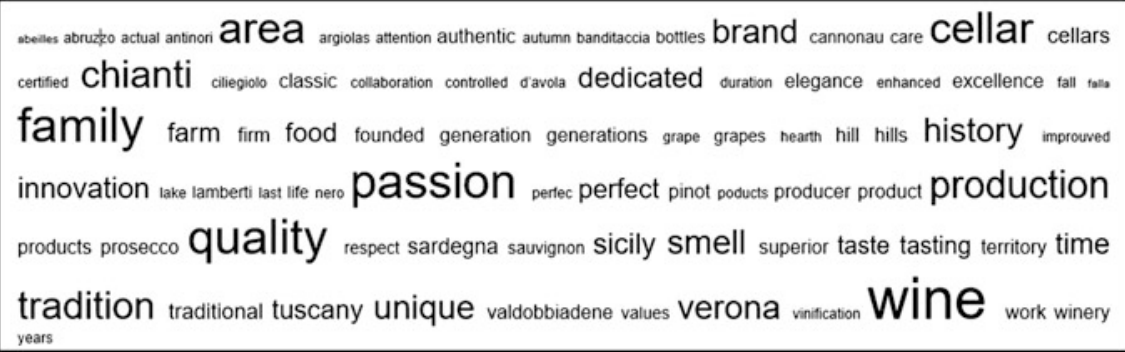

Fig. 5 Homepage: tagcloud within the hedonic node

In order to convey the main lemmas used in the technical file, Figs. 4 and 5 summarize this information.

As we can see from the results shown in Fig. 4, the main associations retrieved from the technical node refer to product certification, area of production, and consortium membership (i.e., Chianti), in order to transmit the quality of the wine.

Lemmas related to the hedonic node of the website homepage refer principally to the heritage of the brand (i.e., family, history, tradition) and the area of production in order to evoke the emotions of consumers.

Finally, in order to answer RQ3, the authors analyzed the results considering only the wineries of the sample included in the official wine rankings in order to find out which type of contents are shared by the most important players in the wine market. Eleven of the 91 wineries were included in the analysis. Seven of out eleven shared the technical files of the product through $\mathrm{QR}$ codes, trying to mix technical aspects and hedonic ones, via various media such as video, text, and images.

Moreover, four out of the eleven 11 most important wineries use QR codes to share their website link. Predominately, the websites feature hedonic aspects in terms of the elements previously discussed.

Results are summarized in Fig. 6. 


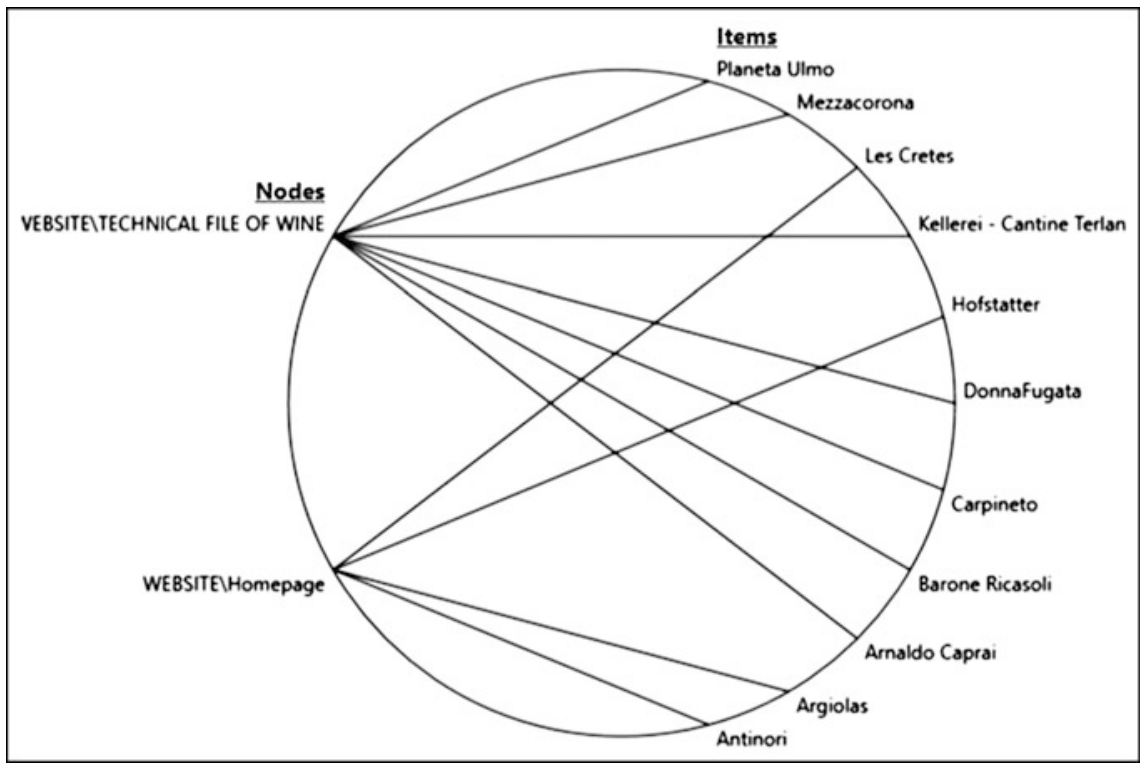

Fig. 6 Homepage: tagcloud within the hedonic node

\section{Conclusions}

While wineries use QR codes in various ways, brand website pages are the most frequent link shared. Within brand-website pages, technical files of the product and the website homepage are the most common links used. The main aspects of the communication observed have been classified in terms of hedonic and functional contents, where the former refers to the pleasure and the amusement of the consumer and the latter refers to technical features of the product. On website homepages, hedonic aspects prevail, whereas, in the wine technical files, functional aspects are more abundant.

Based on the benchmark from the eleven big players included in the sample, technical files of the product seem to be the most effective content, when considering the practices of the market's big players. However, this information should be sustained by other information more related to hedonic aspects. Indeed, consumers may use QR code to uncover additional information than that normally shared on the traditional label. Therefore, wineries should find a balance between functional and organoleptic aspects, useful for demanding and prepared consumers, and hedonic aspects that may be determinant for other consumers that need to be seduced by such contents. From this perspective, wine is not only a beverage, but also a lifestyle product, such as fashion. Therefore communication should reflect this product condition, transmitting both technical information, very important especially for demanding consumers, but also hedonic information able to affect consumer preferences through emotion. 


\section{Limits and Future Research}

This research consists of an explorative analysis of contents shared by QR code technology, including a sample of 91 Italian wine brands. Future research should explore more in-depth the semantic choices of words of the contents shared through QR codes. Furthermore, future research should verify the assumption that there is a relationship between contents shared and the level of brand awareness of the brands considered within the analysis.

Finally, future research should investigate the consumer perspective, exploring the contents that users would like to have and share through QR codes.

\section{References}

Akerlof GA (1970) The market for 'lemons': quality uncertainty and the market mechanism. Q J Econ 84:488-500

Alba JW, Williams EF (2013) Pleasure principles: a review of research on hedonic consumption. J Cons Psychol 23(1):2-18

Bamoriya H (2014) Cross-cultural exploration of consumers' beliefs and behavioral intentions towards QR codes in marketing: an experimental study in India and USA. Acta Universitatis Danubius. Economica 10(4)

Barham E (2003) Translating terroir: the global challenge of French AOC labelling. J Rural Stud 19(1):127-138

Bauer HH, Reichardt T, Barnes SJ, Neumann N (2005) Driving consumer acceptance of mobile marketing: a theoretical framework and empirical study. J Electron Commerce Res

Bazeley P, Jackson K (2013) Qualitative data analysis with N-vivo. Sage Publications Ltd

Begalli D, Capitello R, Codurri S (2012). Social media and web marketing strategies: an exploratory study in the Italian wine sector. Sci Papers 21

Berelson B (1952) Content analysis in communication research. The Free Press, New York

Bisel J (2011) Mobile marketing and QR codes. Hudson Valley Bus J September Issue:21

Brabazon T, Winter M, Gandy B (2014) QR codes and wine media. In: Digital wine. Springer, Singapore, pp 55-85

Bruwer J, Alant K (2009) The hedonic nature of wine tourism consumption: an experiential view. Int J Wine Bus Res 21(3):235-257

Charters S (2006) Aesthetic products and aesthetic consumption: a review. Consump Mark Cult 9 (3):235-255

Chen Y (2006) Marketing innovation. J Econ Manage Strategy 15(1):101-123

Cooper-Martin E (1991) Consumers and movies: some findings on experiential products. Adv Consum Res 18:372-378

Cuellar SS, Claps M (2013) Differential effects of brand, ratings and region on willingness to pay: a hedonic price approach. J Wine Res 24(2):138-155

Easingwood C, Lockshin L, Spawton A (2011) The drivers of wine regionality. J Wine Res 22:19-33

Eliashberg J, Shugan SM (1997) Film critics: influencers or predictors? J Mark 61:68-78. doi:10. $2307 / 1251831$

Farinelli F (2012) Natural resources, innovation and export growth: the wine industry in Chile and Argentina, Maastricht University

Ferrarini R, Carbognin C, Casarotti EM, Nicolis E, Nencini A, Meneghini AM (2010) The emotional response to wine consumption. Food Qual Prefer 21(7):720-725 
Forbes SL, Cohen D, Cullen R, Wratten S, Fountain J (2009) Consumer attitudes regarding environmentally sustainable wine: an exploratory study of the New Zealand marketplace. J Clean Prod 17(13):1195-1199

Geissler GL, Zinkhan GM, Watson RT (2006) The influence of home page complexity on consumer attention, attitudes, and purchase intent. J Advert 35(2):69-80

Giuliani E (2011) Role of technological gatekeepers in the growth of industrial clusters: evidence from Chile. Region Stud Taylor \& Francis 45(10):1329-1348

Grewal D, Roggeveen A, Compeau L, Levy M (2012) Retail value-based pricing strategies: newtimes, newtechnologies newconsumers. J Retailing 88(1):1-6

Grossman SJ (1981) The informational role of warranties and private disclosure about product quality. J Law Econ 24:461-489. doi:10.1086/466995

Haghirian P, Madlberger M, Tanuskova A (2005) Increasing advertising value of mobile marketing-an empirical study of Antecedents. In: Proceedings of the 38th Hawaii international conference on system sciences

Halstead L (2013) Consumer trends in the wine industry for 2013. WineViticult J. www.winebiz. com.au

Handley A (2012) Cracking the mobile code. Entrepreneur, pp 56-57

Hirschman EC, Holbrook MB (1982) Hedonic consumption: emerging concepts, methods and propositions. J Mark:92-101

Kaplinsky R, Fitter R (2004) Technology and globalisation: who gains when commodities are de-commodified? Int J Technol Global 1(1):2004

Kaplinsky R, Readman J (2005) Globalization and upgrading: what can (and cannot) be learnt from international trade statistics in the wood furniture sector? ICC 14(4):679-703

Lockshin L, Corsi AM (2012) Consumer behaviour for wine 2.0: A review since 2003 and future directions. Wine Econ Policy 1(1):2-23

Milgrom P, Roberts J (1986) Price and advertising signals of product quality. J Polit Econ 94:796821

Nelson P (1970) Information and consumer behavior. J Polit Econ 78:311-329. doi:10.1086/ 259630

Nelson P (1974) Advertising as information. J Polit Econ 82:729-754. doi:10.1086/260231

Olsen J, Hermsmeyer J (2008) Direct wine sales and wine 2.0. In: 1. thach and t.matz (eds) Wine: a global business, 2nd edn. Miranda Press, New York

Orth UR, Lockshin L (2007) The global wine business as a research field. Int J Wine Bus Res 19 (1):5-13

Peira G, Bonadonna A, Arnoldi S (2012) Smart tags in the wine sector as a tool for extended packaging: the perception of wine-producing companies in the province of Turin. In: Conference proceeding

Pilone V, De Lucia C, Del Nobile M, Contò F (2015) Policy developments of consumer's acceptance of traditional products innovation: The case of environmental sustainability and shelf life extension of a PGI Italian cheese. Trends Food Sci Technol 41(1):83-94

Raju PS, Lonial S, Mangold W (1993) Differential effects of subjective knowledge, objective knowledge and usage experience on decision making: an exploratory investigation. J Consum Res 15:253-264

Reinstein DA, Snyder CM (2005) The influence of expert reviews on consumer demand for experience goods: a case study of movie critics. J Ind Econ 53:27-51

Reyneke M, Pitt L, Berthon PR (2011) Luxury wine brand visibility in social media: an exploratory study. Int J Wine Bus Res 23(1):21-35

Santini C, Cavicchi A, Rocchi B (2007) Italian wineries and strategic options: the role of premium bag in box. Int J Wine Bus Res 19(3):216-230

Sheth JN, Newman BI, Gross BL (1991) Why we buy what we buy: a theory of consumption values. J Bus Res 22(2):159-170

Shiang-Yen T, Foo LY, Idrus R (2013) Application of quick response (QR) codes in mobile tagging system for retrieving information about genetically modified food. Adv Data Netw Commun Comput. ISBN: 978-960-474-245; ISSN: 1792, 6157, 1417-1426 
Shobeiri S, Mazaheri E, Laroche M (2014) Improving customer website involvement through experiential marketing. Serv Ind J 34(11):885-900

Vaudour E (2002) The quality of grapes and wine in relation to geography: notions of terroir at various scales. J Wine Res 13(2):2002

Wilson J (1998) Terroir: the role of geology, climate and culture in the making of French wines. University of California Press, Octopus Publishing Group

Wohlfahrt J (2002) Wireless advertising, mobile commerce: Grundlagen. Erfolgsfaktoren, Günther Silbere, Wiesbaden, Press, Geschäftsmodelle

Yoo J, Kim M (2014) The effects of home page design on consumer responses: moderating role of centrality of visual product aesthetics. Comput Hum Behav 38:240-247 